\title{
La conceptualización agambeniana de la historia. Hacia una arqueología benjaminiana
}

\section{The Agambenian conceptualization of his- tory: Towards a Benjaminian archaeology}

\author{
NATALIA TACCETTA \\ Universidad de Buenos Aires -CONICET/Instituto de Investigaciones \\ Gino Germani (Argentina)
}

Recibido: 18-9-2012

Aprobado definitivamente: 9-11-2012

\section{RESUMEN}

Giorgio Agamben intenta explorar las condiciones para alguna experiencia futura. Releyendo el ensayo Sobre el programa de la filosofía venidera (1917) de Walter Benjamin, identifica el núcleo de la relación entre experiencia y conocimiento. En ese breve texto, se explicitan las tareas principales del pensamiento y la necesidad de unificar la exigencia de la legitimación del conocimiento y la exigencia de la experiencia. A partir de esta premisa, en este artículo se intenta repensar la experiencia a partir de la noción de «juego» y vincular el planteo gambeniano con una suerte de arqueología benjaminiana de la historia.

\section{PALABRAS CLAVE}

GIORGIO AGAMBEN, WALTER BENJAMIN, ARQUEOLOGÍA, FILOSOFÍA VENIDERA

\section{ABSTRACT}

Giorgio Agamben tries to explore de conditions for some future experience. Rereading Walter Benjamin's essay about the future philosophy (1917), Agamben identifies the core of the rela- 
tionship between experience and knowledge. In that short text, Benjamin explicates the main tasks of thinking and the need to unify the requirement of knowledge and experience. From this premise, this article attempts to rethink the experience from the notion of «play» and link the Agambenian proposition with a sort of Benjaminian archeology of history.

KEYWORDS

GIORGIO AGAMBEN, WALTER BENJAMIN, ARCHAEOLOGY, FUTURE PHILOSOPHY

\section{RELEYENDO EL PROGRAMA DE FILOSOFÍA VENIDERA}

En Clave benjaminiana, Giorgio Agamben intenta explorar las condiciones para alguna experiencia futura. Releyendo el ensayo Sobre el programa de la filosofía venidera (1917) de Walter Benjamin, es posible identificar el nudo gordiano de la relación entre experiencia y conocimiento. En ese breve texto, se explicitan las tareas principales del pensamiento a partir de «la apropiación crítica de su proveniencia esencial» ${ }^{1}$ y el punto más importante del texto está en hacer explícita la necesidad de unificar la exigencia de la legitimación del conocimiento y la exigencia de la experiencia. Para Benjamin, tanto Platón como Kant son los únicos filósofos que, interesados por la justificación del conocimiento, proporcionan herramientas con las cuales es posible asegurarse de que «el conocimiento del que podemos dar razón será, al mismo tiempo, el más profundo». ${ }^{2}$ Hay en esta coincidencia de profundidad y justificación un auténtico programa para la filosofía por venir, pues Benjamin piensa que cuanto más imprevisible y atrevido sea su despliegue, tanto más profundamente luchará por la certeza.

La clave del programa de filosofía venidera estriba en «unificar la exigencia de la legitimación más pura del conocimiento con la demanda del concepto más profundo de la experiencia», ${ }^{3}$ premisa benjaminiana en la que Agamben se detiene para pensar la experiencia contemporánea y su relación con la historia. La limitación de la filosofía kantiana para encontrar un concepto de experiencia más alto está en la elementalidad de la experiencia que da el material para su

1 P. Oyarzún, «Introducción», en Dialéctica en suspenso. Fragmentos sobre historia. Santiago de Chile: Arcis-LOM, 2002, p. 10.

2 W. Benjamin, Sobre el programa de la filosofía venidera. Madrid: Taurus, 1991, p. 162.

3 P. Oyarzún, op.cit., p. 10. Las cursivas son del original. 
noción de conocimiento y es por ello que Benjamin intenta corregirla haciendo que el conocimiento refiera al lenguaje, es decir, concibiendo al conocimiento en su esencia lingüística. El lenguaje dejaría de ser meramente empírico y la experiencia quedaría reconfigurada a partir de una relación más pura con la esencia del lenguaje.

Tal como reseña Oyarzún en la introducción de Dialéctica en suspenso, el pensamiento tradicional se había acercado a la noción de experiencia a partir de los siguientes rasgos fundamentales: La experiencia como momento del devenir del saber. Esto implica la relación del saber con dos aspectos: por un lado, su relación con la repetitividad de los recuerdos a partir de la cual se concibe que se tiene una experiencia; por otro lado, su relación con la cantidad cognitiva de lo experienciable: a) Su ser constitutivamente contingente. En este sentido, ser, además, inanticipable. b) La testimonialidad, es decir, la cualidad cognitiva del experienciar mismo. c) Supone el estar-allí de un ente, un sujeto y la autocertificación de éste.

A la luz de estas consideraciones, se puede afirmar que el concepto de experiencia heredado de la tradición tiene las notas de la singularidad, la inanticipabilidad y la testimonialidad, que configuran un concepto en el que se vinculan muy estrechamente la experiencia con la presencia y la identidad. Estas son, precisamente, las notas que Benjamin cuestiona, pues su perspectiva habilita lo que Oyarzún llama «potencia dislocadora de la experiencia». Ésta incluye la muerte como experiencia indeleble, pues ya no se trata de la experiencia que proporciona significaciones que la doctrina tiene que construir, sino lo indeleble de la muerte como lo que acaece en la idealidad.

Benjamin considera que se ha desarrollado la experiencia de la historia del mundo como historia sufriente. La historia se instaura como despliegue de la significancia en el interior del devenir natural de un destino que cae, por lo que pensar la historia implica aceptar que la muerte es la idea rectora. En este sentido, Oyarzún se explaya del siguiente modo:

Bien podría designarse a la muerte, a la caducidad esencial de lo que 'es', como el instante (Augenblick) de la experiencia -aquello que, sin ser jamás tema de experiencia, es, sin embargo, su condición insuprimible, la condición de su temporalidad-, que rompe de antemano su articulación categorial, y convierte lo que habría sido el campo continuo de despliegue del sujeto en encrucijada del riesgo inesquivable. Instala la esencia de la Erfahrung en la inminencia del peligro $(\text { Gefahr })^{4}$

Benjamin encuentra esta profundidad en la experiencia religiosa como paradigmática de lo profundo. Para el Benjamin maduro, el carácter de la ex-

4 Ibid.,p. 17. 
periencia es el shock sobre el que se construye una temporalidad que vincula experiencia, historia y recuerdo. En términos agambenianos, podría decirse, el shock es una suerte de signatura que marca la experiencia irremediablemente y en su marca la inscribe históricamente dándole forma.

Agamben encuentra que el proyecto fundamental de la modernidad ya implicaba de algún modo la expropiación de la experiencia y es de hecho la ciencia moderna la que nace de una desconfianza frente a ella. Desde Galileo hasta Montaigne pasando por Bacon y Descartes, la experiencia parece incompatible con la certeza y queda subsumida a las leyes científicas que la cuantifican y explican a partir de máximas.

Si la experiencia tradicional mantiene la separación entre experiencia y ciencia, entre el saber humano y el saber divino, lo que separa esos ámbitos es, justamente, una experiencia del límite y es el límite de la muerte. La ciencia moderna anula la separación y transforma la experiencia en método y al lugar de la experiencia en sustrato, en conciencia, en el ego cogito cartesiano. Según Agamben, al remitir a un único sujeto la intersección entre experiencia y ciencia, la ciencia moderna actualiza la conjunción de los saberes humano y divino, que era propia de la experiencia mistérica de la que son testimonio las tragedias griegas. En efecto, es en la experiencia mistérica donde Agamben entiende que el límite entre humano y divino fue sobrepasado con la idea de un páthêma indecible donde el iniciado efectuaba la experiencia de su propia muerte. Es en esta concepción mística donde el sujeto moderno de la experiencia y el conocimiento tienen su fundamento, motivo por el cual Agamben considera que se producen dificultades insuperables.

Según Agamben, la costumbre lleva a representar al sujeto como una «realidad psíquica sustancial», cuando la idea de ese sustrato no era nada obvio en la formulación cartesiana (y es en sí todo un problema metafísico la remisión a la «res»), en la que el sujeto no es más que un sujeto del verbo, un ente puramente lingüístico-funcional. Asimismo, Agamben atribuye a esta insustancialidad las dificultades que tiene Descartes para nombrarlo más allá de la pura enunciación del «yo» («yo pienso», «yo existo»). El sujeto es presentado como sustancia material con propiedades y sensaciones (res cogitans, res extensa) y es sobre esta unión de noûs y psyché, experiencia y conocimiento, que la tradición posterior construye la idea de conciencia psíquica que sustituye al alma cristiana y al noûs griego por la idea de un sujeto metafísico. En esta indagación sobre la experiencia, Agamben reconoce que el ego cogito desplaza o directamente excluye a la fantasía, considerada como irreal, lo que modifica el deseo, el tipo de relación que se establece con él y el modo de considerar la necesidad y el significado de la aventura. La imaginación es expulsada del conocimiento como irreal, cuando en la antigüedad era el vehículo del conocimiento por antonomasia. «En cuanto mediadora entre sentido e intelecto, que hace posible la unión 
en el fantasma entre la forma sensible y el intelecto posible, ocupa en la cultura antigua y medieval exactamente el mismo lugar que nuestra cultura le asigna a la experiencia». ${ }^{5}$ De hecho, es su relación con las imágenes de los sueños lo que une más al sueño con la verdad. La ciencia moderna obliga al nuevo sujeto a asumir la fantasía y «de sujeto de la experiencia, el fantasma se transforma en el sujeto de la alienación mental, de las visiones y de los fenómenos mágicos, es decir, de todo lo que queda excluido de la experiencia auténtica». ${ }^{6}$

En consonancia con la expropiación de la fantasía del ámbito de la experiencia, el deseo se vuelve inapropiable, pues para la psicología clásica, la fantasía y el deseo están intrínsecamente unidos, por lo que la misma satisfacción del deseo se vuelve ajena, alienada o, directamente, imposible. Agamben vincula esta imposibilidad con dos ideas que se relacionan con «experiencia»: por un lado, la experiencia anterior no pretende un métodos hacia el conocimiento, sino que el camino es aporético hacia la experiencia humana; por otro lado, en la modernidad, el único refugio para la experiencia es la aventura que presupone un camino determinado que, ocasional y extraordinariamente, se vuelve exótico y nuevo, cuando lo aporético estriba en lo desconocido.

\section{ENTRE LO DIACRÓNICO Y LO SINCRÓNICO: DE LA HISTORIA A LA TRANSMISIÓN}

La relación entre historia y juego que establece Agamben en Infancia e historia se vuelve particularmente interesante a fin de abrir el problema de la historia a la dimensión estética. El punto de partida es el vínculo entre juego y rito en tanto mantienen «una relación con el calendario y el tiempo»: ${ }^{7}$ el rito fija el tiempo y estructura el calendario; y el juego interviene en el tiempo para alterarlo.

Agamben toma de Benveniste su indagación sobre la relación entre juego y rito para comprobar el vínculo con la esfera de lo sagrado. En algún sentido, el juego proviene de lo sagrado, pero invierte su sentido: «La potencia del acto sagrado reside precisamente en la conjunción del mito que enuncia la historia y del rito que la reproduce». ${ }^{8}$ Aquí aparece una diferencia fundamental pues, en el juego, sobrevive el rito sin que se conserve la forma de lo sagrado, pero el mito - en tanto «fabulación en palabras sugestivas que confiere a los actos su sentido» ${ }^{9}-$ se ha olvidado. En la distinción entre jocus y ludus encuentra Benveniste elementos para una definición de juego: «Se origina en lo sagrado, del cual ofrece una imagen invertida y fragmentada. Si lo sagrado puede definirse

5 Ibid., p. 25.

6 Ibid.,p. 27.

7 G. Agamben, Infancia e historia. Buenos Aires: Adriana Hidalgo editora, 2003, p. 98.

8 Ibid., pp. 99-100.

9 Ibid., p. 100. 
mediante la unidad consustancial del mito y el rito, podríamos decir que hay juego cuando sólo se cumple una mitad de la operación sagrada, traduciendo únicamente el mito en palabras y únicamente el rito en acciones». ${ }^{10}$

Así es que Agamben encuentra una «conexión invertida» entre el juego y lo sagrado que pone en evidencia que el juego es el lugar donde se celebran los ritos y se manipulan objetos y palabras de la esfera de lo sagrado, cuyo sentido ha quedado anulado. En este olvido, lo sagrado se desvincula del tiempo de los relojes y habilita otro tiempo u otra dimensión del tiempo, que es precisamente la del juego: «al jugar, el hombre se desprende del tiempo sagrado y lo 'olvida' en el tiempo humano». ${ }^{11} \mathrm{El}$ juego inaugura un tiempo donde lo sagrado está como desperdigado en y por el tiempo humano, tomando la forma de éste y, como consecuencia de este movimiento, lo viejo se transforma en juego más allá de lo sagrado o profano de su origen. En la conversión en juguete se produce una apropiación que es una profanación o una historización. La esencia del juguete -propone Agamben- es lo Histórico en estado puro, pues allí es donde puede captarse la temporalidad de la historia, que no llega a captarse ni en un monumento, ni en un objeto de anticuario, ni en un documento de archivo. La temporalidad del juguete es la temporalidad humana (y profana), histórica.

Mientras que el valor y el significado del objeto antiguo y del documento están en función de su antigüedad, del modo en que presentifican y vuelven tangible un pasado más o menos remoto, el juguete, fragmentando y tergiversando el pasado o bien miniaturizando el presente -jugando pues tanto en la diacronía como en la sincronía-, presentifica y vuelve tangible la temporalidad humana en sí misma, la pura distancia diferencial entre el 'una vez' y el 'ya no más. ${ }^{12}$

¿Qué significa «jugar»? «Jugar: amurallarse, componer un cuento fantástico, buscar ese objeto único e imposible que podría permitir no sólo saber todo, sino experimentarlo todo a la vez». ${ }^{13}$ Podría agregarse, «hacer historia». Agamben asocia este vínculo entre historia y juego a un proceso de historización o profanación y una miniaturización que es cifra de la historia. En este sentido, el que juega es como un coleccionista que «extrae el objeto de su distancia diacrónica o de su cercanía sincrónica y lo capta en la remota proximidad de la historia». ${ }^{14}$ Esta idea podría asociarse al menos con dos figuras: la del coleccionista y la del arqueólogo.

10 Ibid., p. 100.

11 Ibid., p. 101.

12 Ibid., p. 103.

13 M. Negroni, Pequeño mundo ilustrado. Buenos Aires: Caja Negra, 2011, p. 77.

14 G. Agamben, op. cit., p. 104. 
El coleccionista -tal como lo piensa Agamben- extrae el objeto «de su distancia diacrónica o de su cercanía sincrónica y lo capta en la remota proximidad de la historia». ${ }^{15}$ En Benjamin, cuya filosofía está impregnada del gesto de la colección, la lectura y escritura mismas podrían pensarse como ejercicios de coleccionista que, además de en operación filosófica, se traducen en promesa de justicia. En sus ensayos, hay lugar para los objetos más dispares de la realidad física y cultural: desde recuerdos de niñez hasta la terminología teológica pasando por fragmentos de filosofía marxista al margen de cualquier ortodoxia.

Es, principalmente, en el ensayo sobre Eduard Fuchs que Benjamin se interesó en 1937 por la naturaleza del coleccionismo. Fuchs era propietario de una de las mayores colecciones del mundo de caricaturas, arte erótico y cuadros de costumbres. En «Eduard Fuchs: historia y coleccionismo», Benjamin plantea el doble problema de los caracteres psicológicos del coleccionista y de la naturaleza del coleccionismo en tanto que traslación de la historia de la cultura a un patrimonio de bienes. En relación con el primer problema, Benjamin detecta en Fuchs los atributos de una sensibilidad ligada a un pathos (pathos, sufrimiento y pasión) específico, unos atributos que convierten al coleccionista en un individuo perteneciente a las minorías más excéntricas y complejas de la sociedad: «A la figura del coleccionista, que con el tiempo aparece cada vez más atractiva, no se le ha dado todavía lo suyo. Nada nos impide creer que ninguna otra hubiese podido deparar ante los narradores románticos un aspecto más seductor. Son románticas las figuras del viajante, del jugador, del virtuoso. Pero falta la del coleccionista». ${ }^{16}$

Benjamin insiste luego en el interés que dicha figura presenta para la psicología. Y sabemos que la psicopatología moderna considera abiertamente el coleccionismo como una conducta ligada a naturalezas maníacas y megalómanas, estrechamente relacionada con comportamientos poco saludables como la usura o la avaricia. Sin embargo, más allá de los caracteres psicológicos del coleccionista, Benjamin se interroga, a propósito de Fuchs, sobre el sentido del coleccionismo en relación con la memoria y la recuperación de la historia. Para Benjamin, el coleccionista es un «adivino del destino», como dice en «Imágenes que piensan» y detrás de su conducta se esconde la obsesión de objectualizar el legado del pasado y de convertirlo en un patrimonio de bienes que, sin valor pecuniario alguno, constituyen un incalculable tesoro. El arraigo de la propiedad en el espíritu del coleccionista, y sólo este aspecto de la naturaleza del coleccionismo puede explicar el denominador común de este pathos a lo largo de toda la Historia: buscar, encontrar, clasificar y agrupar parte de la historia y la cultura.

15 Ibid., p. 104.

16 W. Benjamin, Walter, «Eduard Fuchs...», en Discursos interrumpidos I. Madrid: Taurus, 1987, p. 116. 
El coleccionismo como gesto filosófico e historiador (por fuera de los modos estabilizadores de hacer historia), sometido a la inexorabilidad del fragmento, queda evidenciado en el siguiente fragmento del Libro de los pasajes:

Al coleccionar, lo decisivo es que el objeto sea liberado de todas sus funciones originales para entrar en la más íntima relación pensable con sus semejantes. Esta relación es diametralmente opuesta a la utilidad, y figura bajo la extraña categoría de la compleción. ¿Qué es esta 'compleción'? Es el grandioso intento de superar la completa irracionalidad de su mera presencia integrándolo en un nuevo sistema histórico creado particularmente: la colección. Y para el verdadero coleccionista cada cosa particular se convierte en una enciclopedia que contiene toda la ciencia de la época, del pasaje, de la industria y del propietario de quien proviene. La fascinación más profunda del coleccionista consiste en encerrar el objeto individual en un círculo mágico, congelándose éste mientras le atraviesa un último escalofrío (el escalofrío de ser adquirido). [...] Coleccionar es una forma de recordar mediante la praxis y, de entre las manifestaciones profanas de la 'cercanía', la más concluyente. Por tanto, en cierto modo, el más pequeño acto de reflexión política hace época en el comercio de antigüedades. Estamos construyendo aquí un despertador que sacude el kitsch del siglo pasado, llamándolo 'a reunión'. ${ }^{17}$

Benjamin puso al coleccionista en el centro de su reflexión sobre la filosofía de la historia, sobre la historiografía como investigación y la exposición de los objetos que hay que comprender como la necesidad de hacer visible la verdad, como modo de presentar el pensamiento. La figura del coleccionista hace evidente la necesaria figurabilidad del saber sobre la historia. Este «saber muy político, muy actual, inflado de contemporaneidad, debe desembocar sobre la exposición de una colección efectiva y total». ${ }^{18}$ Para Jean-Louis Déotte, se trata de un saber que antes de atravesar los sueños del pasado como los propios sueños y mitologías, deben tener la fulguración del sueño brutal. Implica aceptar que la sola exposición política posible de la historia sea estética y no ya conceptual como para la historia hegeliana o marxiana.

Es en la figura de Fuchs donde se encuentra un pilar para pensar la crítica benjaminiana de la historia cultural socialdemócrata y los lineamientos de la filosofía de la historia. Para Benjamin, el coleccionista es un teórico y un actor político porque resuelve de modo práctico las paradojas que la teoría-según Marx-encontró sin ir más allá. Para indagar adecuadamente sobre esta imagen, hay que tener presente el horizonte filosófico-político de Benjamin, que implica nombres como Klages, Jünger, Jung y Heidegger. De modo que la estética que

17 W. Benjamin, Libro de los pasajes, Madrid: Akal, 2007, p. 223.

18 J.L. Déotte, «Fuchs, l'artiste est un collectionneur», en $L$ 'homme de verre. Esthétiques benjaminiennes. París: L'Harmattan, 1998, p. 208. 
combate es aquella que procede a la «remitologización de los héroes», como propone Déotte. Fuchs le sirve como un personaje a partir del cual pensar el valor de la colección al servicio de la historia de la cultura. En este sentido, sugiere asimismo que el coleccionista es una superficie subjetiva de recepción capaz de acoger cierto tipo de cosas en función de su similitud. Lo que lo convierte en acontecimiento, es posiblemente más el hecho de que una cierta similitud se haya dirigido a él, y menos que a partir de ella él sea sensible a la existencia de tal o cual cosa. La acumulación de cosas, de esas cosas que hay que llamar las inciertas (suspens) alegorías materiales, resulta tal vez de la tentativa misma de llenar el retraso relativo a la irrupción de un cierto registro de la similitud, que puede ser material, figural (figural) o de textura. La serie no-finita de fragmentos colectados estará allí, no para restituir una bella totalidad, sino para pensar, es decir, para delinear los contornos a los que escapa: tal la textura singular de la similitud. Según Déotte, la cabeza de la serie, es decir, la primera pieza adquirida, es por donde comienza una nueva colección y será paradojal: un verdadero acontecimiento visual, gustativo, táctil, sonoro, etc., totalmente improgramado, pero al mismo tiempo una suerte de programa de selección para quien tenga la necesidad de configurar la posibilidad de acontecer. La primera pieza es a la vez la potencia (puissance) de colección. Es porque se ha sido tocado por ella que se decide en cierta forma a conmemorar ese acontecimiento que ella convirtió en coleccionante (collectionnant). El coleccionista se demora siempre sobre el acontecimiento de la primera pieza.

Siguiendo estas consideraciones se entiende que el coleccionista sea el primer nombre de artista para Benjamin porque responde al requerimiento de una cosa que, a diferencia de la ley, no le dice qué debe hacer, sino que se vuelve sensible por el rodeo de una multiplicidad de resplandores. En efecto, en el volumen $H$ [El coleccionista] del Libro de los Pasajes, es posible deducir esta característica del artista contemporáneo de la estética filosófica:

Se puede partir de la idea de que el verdadero coleccionista saca al objeto de su entorno funcional. Pero esto no agota la consideración de este notable comportamiento. Pues no es ésta la base sobre la que funda en sentido kantiano y schopenhaueriano una consideración 'desinteresada', en la que el coleccionista alcanza una mirada incomparable sobre el objeto, una mirada que ve más y ve otras cosas que la del propietario profano, y que habría que comparar sobre todo con la mirada del gran fisonomista. ${ }^{19}$

Benjamin descubre el fondo inapercibido de la estética en general y de la facultad de juzgar kantiana en particular: que de lo que trata la estética se ha suspendido, sus usos han sido puestos entre paréntesis, y que ella no tiene

19 W. Benjamin, op. cit., p. 225. [H 2, 7; H 2 a, 1] 
chance de excitar el libre juego entre el entendimiento y la imaginación de donde proviene el placer estético porque el sujeto no tiene ningún interés en su existencia. Esta cosa de la que trata Kant y que el coleccionista va a proteger antes de proceder a concederle un lugar en esta enciclopedia sistemática que es idealmente una colección, esta cosa antes de toda clasificación es una incertidumbre (suspens).

Estas ideas en torno a la idea de colección en Benjamin implican que, a partir del reconocimiento benjaminiano de que la modernidad, además de potenciar el desarrollo de nuevas tecnologías, conlleva una radical reorientación en la representación y experiencia del tiempo y el espacio, lo que tiene claras consecuencias materiales y conceptuales de la vida cultural en su conjunto. En particular la manera de concebir la historia -ya no identificable con el modelo de historia lineal e irreversible vigente desde la Ilustración- ahora posible de ser pensada a la luz de la espacialización del tiempo en imágenes y la temporalización del espacio en destellos acumulables. En este sentido - tal como sugiere Ana María Guasch- el Libro de los Pasajes hace del «almacenamiento» su razón de ser y sustituye el texto cíclico discursivo por una «acumulación de fichas en las que el autor alterna documentos autobiográficos con citas sobre fuentes ya publicadas y, en general, fragmentos yuxtapuestos en un proyecto abierto y susceptible de múltiples combinaciones, como un álbum de horas movibles o, pensando en clave digital, como una base de datos, archivados en carpetas temporales». ${ }^{20}$ La historia, entonces, queda fragmentada y archivada en anotaciones organizadas en 36 categorías con títulos como «Moda», «Aburrimiento», «Ciudad de sueño», «Fotografía», etc. El montaje es el vehículo para su relato de las galerías del París de fines del siglo XIX en su desafío al progreso lineal y se relaciona con el papel del montaje en las prácticas artísticas de vanguardia después de la Primera Guerra Mundial, en las que los artistas «se apartaban paulatinamente del concepto de disrupción espacial propio del collage» para tomar el desafío de «desarrollar el concepto de historia a partir de metáforas espaciales» ${ }^{21}$

El arqueólogo, por su parte, investiga los objetos resituándolos en una historia que no es la suya, para definir las condiciones de posibilidad de formas de pensamiento que cristalizan a través del tiempo. El arqueólogo describe el «archivo» que, siguiendo la perspectiva de Michel Foucault, se puede entender como el «juego de las reglas que en una cultura determinan la aparición y la desaparición de los enunciados, su remanencia y su borradura, su existencia

20 A.M. Guasch, «El protoarchivo en las prácticas literarias, historiográficas y artísticas: 1920-1929», en Arte y archivo, 1920-2010. Genealogías, tipologías y discontinuidades. Madrid: Akal, 2011, p. 23.

21 Ibid., p. 23. 
paradójica de acontecimientos y de cosas». ${ }^{22} \mathrm{El}$ arqueólogo analiza los hechos discursivos como monumentos articulados históricamente con el poder. En este sentido, la idea de arché, origen, que se encuentra en «arqueología» no apunta al pasado, sino que enfoca el presente. Por eso, para Foucault, «plantear la cuestión de la historicidad de los objetos del saber, de hecho, es problematizar nuestra propia pertenencia a la vez a un régimen de discursividad dado y a una configuración del poder». ${ }^{23}$ Esto implica cuestionar necesariamente el tiempo en el que se vive y a partir del cual se percibe la historia y sus acontecimientos y sujetos.

Siguiendo la propuesta de Déotte, es posible plantear una suerte de arqueología benjaminiana. En efecto, podría decirse, las Tesis de Sobre el concepto de historia, acompañadas de sus variantes y paralipómenos, así como el trabajo sobre Bachofen, permiten comprender el modo en que Benjamin intenta construir y autenticar lo arcaico y la prehistoria, de tal manera que no puedan dar lugar a una «remitologización neoétnica ultramoderna». ${ }^{24}$ Todavía debe instalarse en un cierto ahora del conocimiento, distinguido del presente de la actualidad. Una suerte de instante permanente. Se trata, en definitiva, de pensar la historia como una práctica de la desaparición del pasado en el sentido de posibilitar una «revolución permanente, es decir, una revolución a la orden del día, que entiende a la historia como una fila discontinua de hebras heterogéneas. La discontinuidad radical de la historia implica un retorno del tiempo como siempre posible que no se cristaliza en una trama nueva e inmóvil de la historia.

La figura del arqueólogo en la propuesta benjaminiana debe ser pensada como aquel que introduce la negatividad en el pasado. Un pasado que es complejo, pues la dimensión fundamental para Benjamin es la de un ahora orientado al pasado, esto es, un tiempo-otro dirigido a la prehistoria o lo arcaico. Para esta temporalidad, el presente vivido, el de la actualidad, es inválido. Con Benjamin, es posible pensar un presente del que es posible hacerse cargo políticamente, que implica asumir todas las dimensiones del tiempo en la dualidad continuidad/discontinuidad: el pasado, como patrimonialización de la cultura por los vencedores de la historia y los desaparecidos, frente al cual la tarea es leer la historia no escrita de los vencidos, es decir, hacer una arqueopolítica de las huellas; el presente, ya pasado como acontecimiento vivido en tanto ahora, frente al cual la tarea es prever el porvenir que haga posible el conocimiento del pasado (un ahora de la cognoscibilidad); el futuro, en tanto sueño y actua-

22 J. Revel, El vocabulario de Foucault. Buenos Aires: Atuel, 2008, p. 16.

23 Ibíd., p. 19. El término «arqueología» debe rastrearse, fundamentalmente, en El nacimiento de la clínica: una arqueología de la mirada médica (1963), Las palabras y las cosas: una arqueología de las ciencias humanas (1966) y La arqueología del saber (1969).

24 J.L. Déotte, op.cit., p. 19. 
lización total que propone la tarea de recolectar los destellos de la historia que evite la remitologización. Estas notas constituyen una idea de temporalidad que Déotte describe del siguiente modo: «Temporalidad discontinuista, monadológica. Temporalidad del profeta del presente, de aquel que se establece en el Ahora de la cognoscibilidad. Políticamente, habrá que tender hacia una sola dimensión, un Ahora total, porque dado que los desaparecidos estarán todos allí: es 'la memoria involuntaria de la humanidad liberada'». 25

Por eso el artista-historiador puede hacer un retorno sobre su presente. Al ver aquello que ningún contemporáneo ve todavía, puede ver su propio presente introduciendo una diferencia de tiempos. El porvenir debe hacer justicia a aquello que no ha sido escrito. Esto es, leer el pasado antes de escribir. Aquellos que no han dejado huelas escritas son los vencidos de la historia, los obturados de todas las recensiones historiográficas. Escribir esa historia es, entonces, vengarla. «La acción por-venir será entonces del orden de la venganza. El principio de esperanza para Benjamin, no es de los tiempos que cambiarán para las generaciones futuras, sino la esperanza de poder vengar a los oprimidos del pasado, o el pasado oprimido». ${ }^{26}$ Es posible concluir, entonces, que si hay una política benjaminiana, es la que se deduce de su filosofía de la historia y cuya concepción fundamental es la de la tradición como discontinuidad. Déotte sugiere en relación con esta lógica benjaminiana de la discontinuidad, que es posible pensar el arte de la contemporaneidad -al que llama post-totalitario- como una estética de la desaparición, es decir, «de escritura de aquello que no ha sido jamás escrito, de denominación para aquello que jamás ha sido nombrado, de desarrollo en fin de esta placa fotosensible que es la historia, para la cual jamás se han visto todavía pruebas fotográficas». ${ }^{27}$

La arqueología benjaminiana deviene la apuesta política contemporánea. En efecto, Déotte afirma que no habría una filosofía del tiempo en Benjamin a menos que se piense en el resurgimiento de las temporalidades que estallan contra el tiempo continuo de los relojes. Porque hay temporalidades casi tanto como sectores de lo real (en términos éticos, políticos, estéticos, historiográficos, etc.). En relación con la temporalidad limitada a la estética, se pueden realizar algunas afirmaciones siguiendo estas intuiciones arqueológicas benjaminianas: las obras son dependientes de las épocas de la percepción, determinadas ellas mismas por la temporalidad específica de los aparatos, que mantienen una cierta relación con la ley. De modo que dos arqueologías deben ser distinguidas: la ultramoderna (en términos de Déotte) y la de los desaparecidos. Sea que la 
modernidad tenga la esencia espectral y que haya sido soñado por los muertos, sea que se les rinda homenaje y que sea esperado por las obras del pasado.

Los vencidos no se definen por un mismo programa político. Déotte asegura que no son ni los condenados de la tierra, ni los sin voz o los sin parte, sino que son los sin nombre. Aquellos que no pudieron escribir la historia porque están menos cerca de la verdad de la historia, de aquello que no puede ser tomado en cuenta por el concepto: el acontecimiento. Es su fidelidad al acontecimiento lo que los convierte en sin nombre y sin huella. Es por esta razón que el hombre de las ciudades no debe dejar sus huellas, sino que debe organizar su propia desaparición. Pero, y esto puede pensarse como un límite de la política de la desaparición de Benjamin, la verdadera política coherente de los vencidos, el riesgo supremo, consistirá en que aparezcan los vencedores, nuevos, siempre provisorios, que lleguen definitivamente a vencer a los vencidos borrando todo trazo o rastro.

Es a partir del coleccionista y el arqueólogo como figuras que Agamben quiere establecer la relación entre juego e historia, pues sugiere que, si tal relación existe, «aquello con que juegan los niños es la historia» y «el juego es esa relación con los objetos y los comportamientos humanos que capta en ellos el puro carácter histórico-temporal». ${ }^{28}$ Piensa, además, la conexión entre juego y rito, para destacar el hecho de que, mientras el rito transforma los acontecimientos en estructuras $-\mathrm{y}$, por lo tanto, resuelve la contradicción entre pasado mítico y presente anulando el hiato que los separa y resituando los acontecimientos en la estructura sincrónica-, el juego transforma las estructuras en acontecimientos $-\mathrm{y}$, por lo mismo, destruye la relación pasado/presente desarticulando la estructura en acontecimientos. «Si el rito es entonces una máquina para transformar la diacronía en sincronía, el juego es por el contrario una máquina que transforma la sincronía en diacronía». ${ }^{29}$ Entre sincronía y diacronía, podría decirse, el juego -o la obra estética- resitúa estructuras y acontecimientos en un presente que problematiza el vínculo con el pasado y permite pensar cierta proyección hacia el futuro. Tiene además -como el rito y el juego- la capacidad de producir «distancias diferenciales entre diacronía y sincronía», ${ }^{30}$ en última instancia, tiempo histórico, historia y tiempo humano.

Siguiendo estos recorridos, Agamben propone que el objeto de la historia es la oposición entre diacronía y sincronía -y no la diacronía simplementeque caracteriza a todas las sociedades humanas. Por eso representar el devenir histórico como una sucesión de acontecimientos implica un ocultamiento de la sincronía también existente y constitutiva del tiempo humano, en el que «todo

28 G. Agamben, op.cit., pp. 104-105.

29 Ibid., p. 107.

30 Ibid., p. 108. 
acontecimiento histórico representa una distancia diferencial entre diacronía y sincronía, que instituye entre ellas una relación significante». ${ }^{31}$ Agamben sugiere que los acontecimientos históricos no se revelan ni en la sucesión ni en la simultaneidad, sino en el espacio-distancia entre ellas. Y son, justamente, el rito y el juego los que funcionan instituyendo relaciones significantes en ambos ejes dando como resultado una historia que es consecuencia de las relaciones que rito y juego establecen.

Es interesante notar, en todo caso, que son las obras de arte las que tienen la capacidad de instalar o abrir la discontinuidad en un eje donde la lógica implica que ni el presente se transforme inmediatamente en pasado ni el pasado inmediatamente en presente. En este sentido, se vuelve necesario reconocer que la posibilidad de establecer relaciones significantes entre presente y pasado -y la posibilidad de la sociedad humana, la historia y la reflexión sobre ellaradica, entonces, en el reconocimiento de una discontinuidad radical que no habilita el pasaje de uno a otro (presente, pasado, futuro) ni la transformación total y pura de uno en otro. En efecto, las obras de arte tienen la posibilidad de hacer sobrevivir «residuos» de una y otra esfera, de lo que se deduce una idea de sentido histórico que radica en una topología utópica que tiene lugar en una diferencia significante entre diacronía y sincronía, «entre aión y chrónos, entre vivos y muertos, entre naturaleza y cultura». ${ }^{32}$

En la cultura occidental, sobreviven las que Agamben llama las «larvas» en los Nachleben y en las supervivencias de los significantes del pasado, pero sin su significado original. Las obras de arte tienen la virtud de problematizar este proceso y resituar esas imágenes en sentidos históricos nuevos. Pueden desordenar la cronología y convertirse en significantes desestabilizadores del presente reordenando o subvirtiendo el sentido histórico establecido. Esta lógica es la que guía la definición de historia que propone Agamben: «[...] la regla fundamental del juego de la historia es que los significantes de la continuidad acepten intercambiarse con los de la discontinuidad y que la transmisión de la función significante es más importante que los significantes mismos». ${ }^{33} \mathrm{En}$ clave benjaminiana, la continuidad histórica es la que acepta la discontinuidad -aunque la reubique en «un país de los juguetes o en un museo de las larvas» ${ }^{34}$ y la asume para jugar con ella y, en ese gesto histórico-filosófico, restituye los Nachleben al pasado y los transmite al futuro.

Se pone de manifiesto una idea de lógica histórica alejada de la concepción de la historia en términos de un sentido unificado. Se evidencia la necesidad tanto

31 Ibid., pp. 109-110.

32 Ibid., p. 125.

33 Ibid., p. 127.

34 Ibid., p. 127. 
de la discontinuidad como de una lógica de la experiencia atenta a las interrupciones y la contingencia. De ahí que aceptar el continuum homogéneo y vacío implica resignarse a una concepción dominante del tiempo (desde hace siglos en la cultura occidental) y conlleva cierto sometimiento a la imposibilidad de la revolución, pues esa representación del tiempo «ha terminado así empalideciendo el concepto marxiano de historia: se ha convertido en la brecha oculta a través de la cual la ideología se introdujo en la ciudadela del materialismo histórico».35 El peligro de someterse impulsa a Agamben a explorar la concepción marxiana de la historia, pues considera que una cultura como la occidental, sometida a una concepción del tiempo como un continuum cuantificado e infinito de instantes en fuga, no podía tener una verdadera experiencia de la historicidad.

La noción tradicional de historia está guiada por el término «proceso». La historia adquiere su sentido cuando se piensa en términos de proceso en su conjunto, sin recabar en el instante puntual. La historia es así cronología que, ideológica y políticamente, se homologa a la idea de un fundamento racional, de un progreso continuo e infinito. «Progreso» se convierte en la categoría que traduce ese proceso ordenado cronológicamente y que organiza el conocimiento y, junto con él, la concepción del tiempo y la historia. A partir de influencias que van de Nietzsche a Benjamin, pasando por particulares nociones de Dilthey, Agamben ve que esta concepción «priva al hombre de su propia dimensión y le impide el acceso a la historicidad auténtica» ${ }^{36}$ que, lejos del modelo de las ciencias naturales, permita ver todo lo que queda sepultado por el aparente triunfo del historicismo.

¿Cómo acceder a una concepción más auténtica de la historicidad? ¿Cuál es el aparato teórico que orienta a Agamben en la búsqueda de la relación verdadera entre cultura, experiencia e historia? Desplazada la concepción de la historia como un sentido unificado, ¿cómo concebir el sentido histórico o los sentidos históricos alternativos? La propuesta benjaminiana de la historia responde en parte a estos interrogantes, pero la lógica agambeniana ve necesaria una indagación atenta a la noción de historia para Marx, en tanto uno de sus referentes principales:

Para él [Marx] la historia no es algo en lo que el hombre cae, es decir que no expresa simplemente el ser-en-el-tiempo del espíritu humano, sino que es la dimensión original del hombre en cuanto Gattungswesen, en cuanto ser capaz de un género, capaz de producirse originalmente no como mero individuo ni como generalidad abstracta, sino como individuo universal. Por lo tanto, la historia no está determinada, como en Hegel y el historicismo que proviene de él, a partir de la experiencia

35 Ibid., p. 132.

36 Ibid., p. 141. 
del tiempo lineal en cuanto negación de la negación, sino a partir de la praxis, de la actividad concreta como esencia y origen (Gattung) del hombre. ${ }^{37}$

La praxis en la que el hombre se sitúa como origen y naturaleza es el primer acto histórico, el acto de origen de la historia, es decir, como la «conversión de la esencia humana en naturaleza para el hombre y la conversión de la naturaleza en hombre». ${ }^{38}$ La historia es, para Marx, su naturaleza, la pertenencia original del hombre para sí como género, del que la alienación lo aparta. Agamben lo resume del siguiente modo: «El hombre no es un ser histórico porque cae en el tiempo, sino todo lo contrario, únicamente porque es un ser histórico puede caer en el tiempo, temporalizarse». ${ }^{39} \mathrm{Si}$ la concepción del tiempo no se corresponde con una sucesión continua e infinita de instantes puntuales, la historia auténtica tiene un acceso limitado por una experiencia del tiempo que no se adecua a su historia de la historia y hace que la crítica del instante sea la condición sine qua non para una nueva experiencia del tiempo.

El marxismo es, naturalmente, una de las fuentes que nutre la concepción benjaminiana de la historia. En Aviso de incencio, Michael Löwy agrega, además, el romanticismo alemán y el mesianismo judío. A partir de estas influencias, Benjamin elabora una nueva manera de concebir la historia, pensar sus agentes y repensar la tarea del historiador. Del romanticismo toma «una estructura de la sensibilidad que se manifiesta en todas las esferas de la vida cultural»;40 del mesianismo y el marxismo, recupera, entre otras cosas, las imágenes utópicas -mesiánicas y revolucionarias- contra lo que llama «la informe tendencia progresista». El mesianismo es central para pensar el tiempo y la historia y el deber de rememoración que queda inscripto en ellos. Pero las intuiciones «antiprogresistas» de Benjamin -como las llama Löwy- se articulan en su discurso con una visión fuertemente crítica al marxismo evolucionista vulgar para concebir la revolución como la interrupción histórica que lleva a la catástrofe. Una catástrofe que es posibilitadora de la emancipación de las clases oprimidas, pues, en la concepción benjaminiana, la historia se representa como permanente catástrofe, como fuerte crítica al progreso y se identifica «cultura» con «barbarie».

A la idea de un progreso -fundado en la idea de catástrofe- de la especie humana en la historia, propia de la socialdemocracia y el historicismo, Benjamin contrapone una conciencia revolucionaria que quiebra el tiempo homogéneo y vacío, que hace sobresaltarse al continuum de la historia. Al instante vacío le opone un «tiempo-ahora» (Jetzt-Zeit), en tanto detención mesiánica

37 Ibid., p. 145.

38 Ibid., p. 145.

39 Ibid., p. 145.

40 M. Löwy, Aviso de incendio. México: Fondo de Cultura Económica, 2004, p. 18. 
del acontecer. Benjamin ataca, fundamentalmente, las causas que condujeron a la catástrofe e intenta pensar una concepción de la historia que no esté en complicidad con ella.

La historia no es entonces, como pretende la ideología dominante, el sometimiento del hombre al tiempo lineal continuo, sino su liberación de ese tiempo. El tiempo de la historia es el cairós en que la iniciativa del hombre aprovecha la oportunidad favorable y decide en el momento de su libertad. Así como al tiempo vacío, continuo e infinito del historicismo vulgar se le debe oponer el tiempo pleno, discontinuo, finito y completo del placer, del mismo modo al tiempo cronológico de la pseudohistoria se le debe oponer el tiempo cairológico de la historia auténtica. ${ }^{41}$

Agamben asocia una historia auténtica con un verdadero tiempo histórico en clave materialista, pues éste no es quien persigue a lo largo del tiempo un progreso continuo, sino aquel que en todo momento está en condiciones de detener el tiempo: «Un concepto específico de presente como el del «tiempoahora» [será] ése en el cual se han esparcido astillas del mesiánico», tal como lo expresa en Sobre el concepto de historia. Para Benjamin, las revoluciones son interrupciones en la cronología; de hecho, una nueva cronología es una transformación cualitativa del tiempo, una cairología, que no pueda ser reabsorbida por el continuum.

En «Caracterización de Walter Benjamin», Adorno describe el método benjaminiano como «micrológico y fragmentario», en su objetivo de que la mínima parte de la realidad y el mundo como un todo están en equilibrio y que interpretar fenómenos en el modo materialista significa explicarlos en su singularidad, refiriéndolos a tendencias materiales y luchas sociales. En este sentido, una concepción de la historia en términos materialistas conlleva que la estructura y la superestructura no se hallan percibidas en cada ocasión como distintas y luego puestas en relación desde la perspectiva dialéctica, sino que -tal como propone Agamben- «Sólo es materialista el punto de vista que suprime radicalmente la separación entre estructura y superestructura porque se plantea como único objeto la praxis en su cohesión original, es decir, como 'mónada' (en la definición de Leibniz, mónada es una sustancia simple, 'sin partes')». ${ }^{42}$

A la luz de la interpretación benjaminiana del tiempo y la historia, Agamben asume que la tarea de garantizar la unidad de lo «sin parte» se le encomienda a la filología con el objeto de invertir los polos de lo que es una representación de la facticidad. La «mónada» de la praxis se presenta, para Agamben, como una «pieza textual» a la que el filólogo debe restituir integridad fáctica «donde están unidos originalmente en 'mítica rigidez' tanto los elementos de la estructura

41 G. Agamben, op.cit., p. 154.

42 Ibid., p. 181. 
como los de la superestructura». ${ }^{43} \mathrm{Y}$ lo que la filología recoge debe ser historizado a través de una operación que Benjamin califica como Aufhebung de la filología. Este término alemán puede ser entendido como "superación», pero también como «cesura» $\mathrm{O}$ «abolición» y, en cualquier caso, implica la remisión a la idea de experiencia histórica, pues sólo ésta puede animar el objeto «despertándolo de la mítica rigidez filológica». ${ }^{44}$ Este pasaje entre filología e historia adquiere pleno sentido en la relación que Benjamin establece entre los conceptos de «contenido fáctico» (Sachgehalt) y «contenido de verdad» (Wahrheitsgehalt), cuya unidad originaria y cuya separación en el curso del tiempo caracterizan la esencia e historicidad de la obra de arte. Esta relación plantea el modelo de lo que desde la perspectiva benjaminiana podría ser la conexión entre estructura y superestructura. Agamben señala que materialista histórico es quien concibe el contenido fáctico y el contenido de verdad, la estructura y la superestructura como identificables. «Y así como el contenido fáctico y el contenido de verdad están originariamente unidos en la obra y sólo en su duración temporal aparecen disociados, del mismo modo la estructura y la superestructura, unidas en la praxis, se separan en la obra que sobrevive en el tiempo». ${ }^{45}$

La tarea de la crítica es reconocer en la obra -y en su facticidad y como «pieza textual»- la unidad entre estructura y superestructura que queda petrificada en ella. En este sentido, «la estructura es la superestructura» es una afirmación especulativa -ni causal, ni dialéctica- que pone en evidencia nuevamente que hay que dejar de identificar la historia con una concepción del tiempo como proceso lineal y continuo, y asumir que la dialéctica, como categoría histórica, no conlleva la superación en tanto proceso lineal, sino justamente la abolición o cesura. Por eso la «concepción del tiempo debe ser adecuada a una dialéctica que verdaderamente se haya liberado de todo 'abstraimiento'». ${ }^{46}$

En «Programa para una revista», Agamben parte de una escisión fundamental que se ha producido en la cultura occidental entre «el patrimonio cultural y su transmisión, entre verdad y transmisibilidad, entre escritura y autoridad», ${ }^{47}$ para pensar la relación entre historia y transmisión. Según su interpretación, la cultura no ha tomado ninguna conciencia de ese apartamiento, que consiste en un distanciamiento entre contenido fáctico y contenido de verdad, de manera que «hay una verdad, pero no la posibilidad de transmitirla; existen medios de transmisión, pero no transmiten ni enseñan nada». ${ }^{48}$ Esta desconexión se

43 Ibid., p. 182.

44 Ibid., p. 182.

45 Ibid., p. 185.

46 Ibid.,p. 186. Con «abstraimiento» se traduce «astrattezza» del original italiano. Podría referirse tanto distracción como descuido. Nota del traductor de la edición citada.

47 Ibid., p. 199.

48 Ibid., p. 200. 
manifiesta en cada ocasión como un contraste entre lo viejo y lo nuevo, lo pasado y el presente, e impide ver que ambos polos forman parte de un mismo inaccesible, pues, en efecto, el pasado se ha vuelto tanto una obsesión como un imposible de alcanzar.

El diagnóstico agambeniano señala que «extrañamiento y ready-made, détournement y cita fueron en nuestro siglo las últimas tentativas ${ }^{49}$ para reconstruir una relación con el pasado, que confirman una y otra vez que el presente está formado por ruinas. En este sentido, la perspectiva de Agamben insta a realizar no una simple destrucción de la tradición, sino una «destrucción de la destrucción» (como hace con la estética en El hombre sin contenido), a partir de la cual se produzca la destrucción de la transmisibilidad en tanto carácter original de la cultura.

Todo este proceso lleva implícita una tarea fundamental: la de asumir que abolir la escisión entre la cosa transmisible y el acto de transmisión, entre escritura y autoridad, implica soportar que la historia ya no puede ser identificada con un proceso continuo, lineal e infinito y que, por consiguiente, se vuelve imperioso «tomar consciencia de que las categorías históricas y las categorías temporales no son necesariamente lo mismo». ${ }^{50}$ En consonancia con esta idea, aparece como horizonte posible explorar nuevas aristas de la relación entre historia y tiempo y de su vínculo con la experiencia a fin de que puedan ser concebidos nuevos modos de constituir el sentido histórico, que se funden en la discontinuidad, la interrupción y el shock benjaminiano. Dar por tierra el tiempo continuo y vacío del historicismo significa asumir un tiempo «pleno, separado, indivisible y perfecto de la experiencia humana concreta». ${ }^{51}$

Al tiempo cronológico de la pseudohistoria -que se ha olvidado de la experiencia y de la experiencia de la experiencia-, la historia auténtica propone un tiempo cairológico, interrupción, inmediatez y dialéctica inmóvil..$^{52}$ Instalar al sujeto en este territorio nuevo, quiere decir sustraerlo a la duración mensurable e inscribirlo en «un tiempo histórico que no es ni el tiempo puntual ni la eternidad». ${ }^{53}$ La tarea histórica consiste en posibilitar el advenimiento del tiempo pleno que supone la liberación del goce ahistórico, para acceder a una temporalidad placentera, transformadora cualitativamente del tiempo. «Tal es el tiempo que se experimenta en las verdaderas transformaciones subjetivas y en los momentos de cambio revolucionario en la historia, que interrumpen una

49 Ibid., p. 201.

50 Ibid., p. 207.

51 Ibid., p. 208.

52 Ibid., p. 208.

53 J. Milmaniene, El tiempo del sujeto. Buenos Aires: Biblos editorial, 2005, p. 95. 
cronología asentada en el tiempo cuantificado y continuo, para reafirmar una 'kairología' que impide cualquier retroceso y restauración regresiva». ${ }^{54}$

Es en la filología y no en la historiografía donde Agamben encuentra el modelo para una concepción de la historia que, independizándose de la cronología, se libere «del mito de su arquetípico aislamiento». ${ }^{55}$ Lo que hace la filología es producir un origen, pero no como acontecimiento arquetípico separado, de otro tiempo, sino producir un origen histórico y no fuera de la historia. No es un origen porque es anterior o más antiguo, sino porque es un punto en el eje sincrónico con el cual se puede medir el presente -también diacrónicamente. Agamben propone que ese origen sea concebido como una separación y una diferencia entre diacronía y sincronía, una arkhé histórica que no es un instante anterior en la cronología. Se define así una suerte de «historicidad sincrónica». ${ }^{56}$ Para Agamben, «La filosofía extrae efectivamente al mito de su rigidez arquetípica y de su aislamiento y lo devuelve a la historia». ${ }^{57}$ La filología produce un origen desvinculado de la esfera de lo ritual sin someterlo a una legalidad teleológica. Así lo expresa en Sobre el concepto de historia: «La idea de un progreso del género humano a lo largo del curso de la historia no puede separarse de la idea de su prosecución en un tiempo vacío y homogéneo. La crítica de la idea de tal prosecución debe constituir la base misma de la crítica de la idea general de progreso».

\section{REFERENCIAS BIBLIOGRÁFICAS}

AGAMBEN, G., Infancia e historia. Buenos Aires: Adriana Hidalgo editora, 2003. BENJAMIN, W., «Eduard Fuchs», en Discursos interrumpidos I. Madrid: Taurus, 1987.

BENJAMIN, W., Sobre el programa de la filosofía venidera. Madrid: Taurus, 1991. BENJAMIN, W., Libro de los pasajes, Madrid: Akal, 2007.

DÉOTTE, Jean-Louis, «Fuchs, l'artiste est un collectionneur», en L'homme de verre. Esthétiques benjaminiennes. París: L'Harmattan, 1998.

GUASCH, Ana María, «El protoarchivo en las prácticas literarias, historiográficas y artísticas: 1920-1929», en Arte y archivo, 1920-2010. Genealogías, tipologías y

54 Ibid., p. 95.

55 G. Agamben, op. cit., p. 209.

56 Agamben elige esta expresión tomándola de Roman Jakobson, quien, en Principios de fonología histórica, introduce la historicidad y la teleología como categorías estáticas y sincrónicas a fin de abrir la dimensión del lenguaje para mediar entre la lingüística descriptiva y la lingüística histórica.

57 Agamben,op.cit., p. 211. 
discontinuidades. Madrid: Akal, 2011.

LÖWY, M., Aviso de incendio. México: Fondo de Cultura Económica, 2004.

MILMANIENE, J., El tiempo del sujeto. Buenos Aires: Biblos editorial, 2005.

NEGRONI, M., Pequeño mundo ilustrado. Buenos Aires: Caja Negra, 2011,

OYARZÚN, P., «Introducción», en Dialéctica en suspenso. Fragmentos sobre historia.

Santiago de Chile: Arcis-LOM, 2002.

REVEL, J., El vocabulario de Foucault. Buenos Aires: Atuel, 2008.

NAtalia TACCETTA es investigadora en la Universidad de Buenos Aires - CONICET/Instituto de Investigaciones Gino Germani.

Líneas de investigación:

Filosofía de la historia, estética.

Publicaciones recientes:

(2012), «Aproximaciones al hacer del hombre desde la perspectiva de Giorgio Agamben. La deriva de Guy Debord», revista Paralaje No 8, 2012, Chile, ISSN 0718-6770.

(2012), Agamben y lo político, Prometeo Libros, Buenos Aires, 2012.

Dirección electrónica: ntaccetta@gmail.com 
